\title{
MAPEAMENTO DO RISCO DE PREJUÍZO COMO MEDIDA DE GESTÃO E ADAPTAÇÃO ÀS INUNDAÇÕES
}

\author{
DAMAGE RISK MAPPING AS A FLOOD MANAGEMENT AND ADAPTATION MEASURE
}

\section{Amanda Wajnberg FADEL, Guilherme Fernandes MARQUES, Joel Avruch GOLDENFUM}

Pós-Graduação em Recursos Hídricos e Saneamento Ambiental, Instituto de Pesquisas Hidráulicas, Universidade Federal do Rio Grande do Sul, Campus do Vale, Porto Alegre-RS. Emails: awfadel@outlook.com; guilherme.marques@ufrgs.br; joel@iph.ufrgs.br

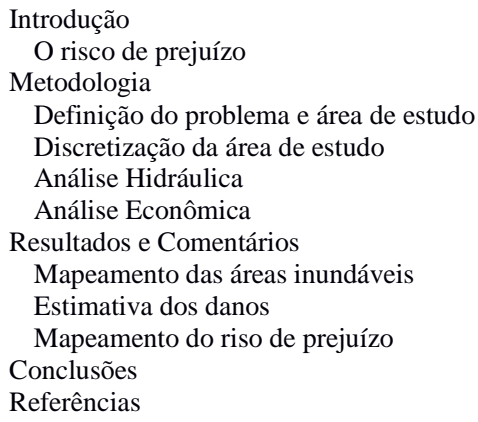

\begin{abstract}
RESUMO - No Brasil, é frequente a abordagem de "gestão de crise" ao lidar com eventos de cheias; enquanto que as medidas preventivas são mais raras. A avaliação do risco de prejuízo é um aspecto importante ainda não incorporado nas análises de investimentos desse controle, sem o qual torna-se difícil identificar medidas que sejam eficazes sem onerar excessivamente o município ou os usuários. O presente artigo incorpora o risco de prejuízo às metodologias já existentes de estimativas do dano por profundidade de submersão, agregando um ponderador de frequência de recorrência desse dano. Foram utilizados simulação hidráulica e avaliação econômica, possibilitando relacionar a frequência de um evento às profundidades de submersão da mancha de inundação e características socioeconômicas de cada área. Os resultados permitem concluir que em áreas urbanas com densa ocupação consolidada, mesmo com menor magnitude da inundação, o risco pode ser elevado, justificando ações prioritárias para sua mitigação. Já para as localidades mais afastadas do rio, tanto probabilidade quanto ocupação diminuem, reduzindo consequentemente o risco, devido à menor exposição da população ao perigo. Esses resultados estão diretamente relacionados com as características de relevo e o padrão de ocupação, que determinam a caracterização dos danos da planície de inundação da região.

Palavras-chave: risco de prejuízo, gestão de risco de inundações, mapeamento de inundações, medidas de adaptação.
\end{abstract}

\begin{abstract}
In Brazil, flood events are still often dealt with a "crisis management" approach, instead of a more preventive, riskbased methodology. The assessment of the damage risk is an important aspect in this context, albeit not yet fully incorporated into the flood control investment analysis, limiting the identification of cost-effective flood management measures. This article incorporates the risk factor to the existing damage estimates methodologies with depth of submersion, considering the recurrence frequency of such damage. Hydraulic simulation was used and economic evaluations were conducted, linking the frequency of an event with the flood depths and socioeconomic characteristics of each area. Results show that areas with dense and consolidated urbanization, even with smaller flood magnitude, presents higher risks, justifying the priority in mitigating actions. For locations further away from rivers, the probability and occupancy decrease, reducing both the risk and the number of individuals exposed to danger. These results are directly related to the terrain characteristics and the type of occupation, which delimits the flood plain and expected damage in the region.
\end{abstract}

Keywords: damage risk, flood risk management, flood mapping, flood adaptation measures.

\section{INTRODUÇÃO}

No Brasil, é comum o registro de situações de calamidade pública em municípios atingidos por inundações. No entanto, também é frequente que nessas localidades não existam medidas para o gerenciamento das inundações, mesmo com a iminência de ocorrência de eventos desse tipo. Embora se encontrem exemplos bem sucedidos de organização municipal, principalmente a cargo das defesas civis, a avaliação do risco de prejuízo ainda não é incorporada nas análises de investimentos em medidas de controle de cheias.

Os principais meios de proteção adotados geralmente estão relacionados a medidas estruturais (como diques e barragens), uma vez que essas medidas já estão bem consolidadas no país como forma padrão para a proteção contra inundações. Essas medidas são normalmente bem recebidas pela população por serem obras de grande visibilidade e diminuírem quase que imediatamente a frequência das inundações (Tucci, 2009).

Outra alternativa é o gerenciamento do uso e ocupação do solo por meio de zoneamentos, determinando as áreas sujeitas a danos por inundação e ordenando sua ocupação conforme a probabilidade de inundar. Tal ordenação pode, contudo, limitar o uso do solo e 
apresentar-se como medida impopular.

A avaliação e combinação das diferentes formas de proteção contra cheias faz parte da elaboração de um bem sucedido e eficaz plano focado na gestão do risco, no lugar da gestão de crise (comum quando o planejamento é deficiente). Entretanto, metodologias para a comparação das diferentes alternativas, que sirvam de subsídio para o poder público decidir por uma ou outra medida - ou ainda uma combinação de diferentes medidas - são pouco exploradas no Brasil.

O risco pode ser entendido como a relação entre probabilidade de ocorrência de certo evento e suas consequências, sendo influenciado pelos fatores perigo, exposição e vulnerabilidade (Kobayashi \& Porter, 2012).

É dessa necessidade que surgem propostas por gestão com base no risco de inundação (ou risco do prejuízo). Nesse tipo de análise, é atribuído, a cada magnitude dos eventos uma probabilidade de ocorrência e o respectivo prejuízo, que estará intimamente ligado às características da região afetada. Com isso, é possível traçar estratégias de investimento, compatibilizando medidas a serem propostas àquelas já existentes, para considerar todos os benefícios e custos das políticas de gestão de inundação.

Nesta análise, inicialmente é necessário especificar qual a probabilidade de ocorrer dado prejuízo (ou seja, quão grande é o risco); determinar as potenciais formas de redução de risco e seus respectivos custos; e, finalmente, determinar se a forma de redução de risco é adequada, comparando-se o custo de investimento ao respectivo benefício.

De todas as fases dessa análise, aquela que demanda maior esforço é a estimativa dos prejuízos, o que tem motivado grande número de estudos de gerenciamento de inundações com foco na determinação das curvas cotadano. Curvas desse tipo possibilitam a avaliação global de prejuízos diretos causados por inun-dações segundo as profundidades de submersão em uma dada área (Machado et al., 2005).

A determinação desta curva foi inicialmente proposta por Penning-Rowsell \& Chatterton (1977), partindo da obtenção da curva chave local para produzir a curva de dano de inundação, a qual permite a associação do nível de cheia com o prejuízo. Entretanto, essa curva apresenta o prejuízo máximo que pode ser causado por inundações de diferentes magnitudes, sem considerar a frequência de tais eventos.

A partir somente da curva cota-dano, podese inferir que a melhor alternativa seria propor medidas de controle de forma a evitar o maior prejuízo possível; contudo, ignora-se a informação de que tal evento possa ser tão raro que não compense o seu investimento a longo prazo. Por outro lado, eventos resultando em danos de baixa magnitude e valor, porém elevada frequência, podem acumular prejuízos significativos ao longo do tempo.

Cunha \& Taveira-Pinto (2011) apresentam uma metodologia semelhante utilizando o programa HEC-FDA (Flood Damage Reduction Analysis). Tal método, entretanto, permite realizar uma análise de dano baseada no risco de inundação, calculando o prejuízo anual esperado e não apenas a determinação da curva de dano. Além disso, a valoração das estruturas potencialmente atingidas pela inundação foi realizada por meio de um inventário local e consulta a agências imobiliárias.

Uma vez que não é simples a realização de inventários de danos e conteúdo dos domicílios em área de risco de inundação, Tachini (2010) propôs uma metodologia de análise de danos a partir de uma abordagem sintética, sendo que os prejuízos foram estimados a priori com base num imóvel padrão, tipo unifamiliar de um pavimento, e extrapoladas para os demais tipos de ocupação por meio de um fator de multiplicação.

Aproximando-se mais das metodologias de gestão de risco, Foudi et al. (2014) estudaram uma proposta de ordenação do uso e ocupação da terra com base na estimativa de risco de inundação. Para isso, foram estimados os impactos para os setores residenciais, não residenciais, agrícolas e ambientais, na cidade de Zaragoza (Espanha). A metodologia propõe que o risco de inundação depende de dois fatores. O primeiro seria o dano anual esperado, que é utilizado para determinar locais e setores prioritários. O outro fator compreende as curvas dano-probabilidade, as quais fornecem informações da distribuição 
do risco, considerando a intensidade da cheia para determinar a magnitude do dano. Com isso, é possível estimar uma distribuição espacial do risco, indicando as localidades com maior prejuízo, orientando, assim, as políticas de prevenção.

Enquanto que as curvas de danos trabalham apenas com a magnitude do evento, ou seja, qual o prejuízo máximo que ocorrerá quando a inundação atingir uma certa cota, as curvas de risco agregam a informação da frequência de ocorrência de tal dano. A avaliação dos prejuízos de inundação utilizando o risco de prejuízo possibilita, portanto, a incorporação de um ponderador que considera não só a magnitude do evento, mas também a recorrência do dano.

Em regiões onde a planície de inundações é densamente ocupada, mesmo que as cheias atinjam cotas baixas (e com isso um dano relativamente menor), a frequência de recorrência é alta. Nesse caso, o risco de prejuízo pode ser significativo se comparado ao associado a eventos extremos, com grande magnitude, mas cuja frequência é baixa. Além do que geralmente seria proposto em um primeiro momento - de se investir massivamente em medidas capazes de conter as grandes cheias, soluções as quais tenham como foco as inundações menores e mais frequentes também podem gerar benefícios significativos.

Entretanto, caso a região de estudo tenha já uma ocupação ordenada da planície de inundação, com um zoneamento efetivo, o dano associado às áreas mais frequentemente inundáveis será o menor possível, fazendo com que o risco de prejuízo também seja reduzido. Nesse caso os altos prejuízos decorrentes de inundações extremas, embora tenham baixa frequência de ocorrência, acabam resultando em um risco maior.

Exemplos de como produzir uma curva de risco (ou dano esperado) já foram apresentados por diversos estudos brasileiros e no exterior. A determinação do dano a partir de dados reais obtidos em zonas sinistradas (a posteriori) foi utilizado por Machado et al. (2005) com a identificação dos danos decorrentes de um evento de inundação de referência, com aplicação de questionários junto à população das áreas afetadas em um evento ocorrido em 2002 em Minas Gerais. Vaz (2015) e Nagem (2008) apresentam avaliações do custo das inundações das áreas que seriam atingidas para diferentes cotas, com os prejuízos proporcionais aos registrados em eventos reais; mas, ainda que tais níveis estejam associados à probabilidade de ocorrência, os TRs servem apenas como um referencial para delimitação das manchas de inundação.

Na mesma linha, Tachini (2010) e Salgado (2005) também apresentam possibilidades para estimativa de danos de eventos reais e associados a diferentes cotas, com o diferencial de propor uma metodologia à priori de análise. Contudo, grande parte do que é proposto para o gerenciamento dos prejuízos decorrentes das inundações no país não é referente ao uso do dano esperado, sendo utilizadas, em sua maioria, outras métricas de avaliação que não consideram a frequência de ocorrência do dano.

O presente artigo traz como contribuição para a gestão das inundações a incorporação do risco de prejuízo, agregando às metodologias já existentes de estimativas do dano por profundidade de submersão um ponderador de frequência de recorrência desse dano. Foram utilizados em conjunto simulação hidráulica e avaliação econômica, de modo a relacionar a frequência de um dado evento às profundidades de submersão ao longo da mancha de inundação e características socioeconômicas de cada unidade de área.

Os resultados e métodos aqui apresentados são úteis para auxiliar planejadores urbanos a propor planos de ações de enfrentamento das inundações com base tanto na ocupação territorial quanto no regime hidrológico local. Ao mostrar que cheias de baixa magnitude, porém alta frequência, podem resultar em prejuízos acumulados significativos ao longo do tempo, o artigo busca destacar a necessidade de medidas de adaptação e convivência com inundações. Com emprego das curvas de risco na gestão, apresenta-se uma complementação ao que vem sendo aplicado, de propor medidas para a maior proteção possível sem necessariamente contrapor o grau de proteção ao benefício efetivo que tais medidas trarão à população. A metodologia é apresentada por meio de sua aplicação no município de Lajeado 
(RS), escolhido devido à elevada frequência e vulnerabilidade às inundações.

\section{$\mathrm{O}$ risco de prejuízo}

O dano da inundação está associado à ocupação da região, de modo que o crescente número de ocorrências de eventos com danos é acompanhado pela expansão populacional. Fenômenos naturais de grandes cheias sempre existiram; no entanto, no momento em que a população se estabelece em localidades propensas à sua ocorrência, temos como resultado o acontecimento dos desastres naturais (Goerl \& Kobiyama, 2013).

Os desastres naturais foram definidos pela Instrução Normativa $n^{0} 01 / 2012$, do Ministério da Integração, como "aqueles causados por processos ou fenômenos naturais que podem implicar em perdas humanas ou outros impactos à saúde, danos ao meio ambiente, à propriedade, interrupção dos serviços e distúrbios sociais e econômicos" (BRASIL, 2012). Com isso, no Brasil foram assumidas as classificações de desastres constantes no Banco de Dados Internacional de Desastres
(EM-DAT), as quais incluem inundações, enxurradas, efeitos de maré e deslizamentos como Desastres Naturais Hidrológicos.

O avanço da população aumenta sua exposição aos fenômenos naturais, de modo que desastres os quais antes apenas causavam danos quando oriundos de grandes eventos, agora ocorrem com maior frequência.

É por isso que, ao se pensar na gestão de risco de inundações, é inevitável que se incorpore nas estimativas de danos à probabilidade de ocorrência do prejuízo.

A avaliação de risco é definida pela relação entre a probabilidade de ocorrência de um evento qualquer e a magnitude de suas consequências (Jacobs \& Worthley, 1999, segundo Deckers et al., 2010).

Traduzindo para o contexto de inundações, o risco será, portanto, proporcional tanto ao tempo de retorno de um evento quanto ao prejuízo causado por essa cheia.

Além disso, o risco de inundação pode ser influenciado por outros três fatores, segundo Kobayashi \& Porter (2012): perigo, exposição e vulnerabilidade.

\section{METODOLOGIA}

A determinação do prejuízo de inundação teve como objetivo principal a antecipação dos possíveis efeitos que uma cheia poderia causar na região. O montante efetivo do prejuízo foi associado à respectiva probabilidade de ocorrência, incorporando o conceito de risco, no qual o prejuízo real esperado de uma inundação está relacionado com a probabilidade de ocorrência do dano:

$$
\begin{aligned}
& R P_{T R}=p_{T R} \times D_{T R} \\
& R P_{\text {unit }}=\frac{R P_{T R}}{A_{i}}
\end{aligned}
$$

Onde:

$R P$ : risco de prejuízo de uma dada área inundada; TR: tempo de retorno do evento de cheia; $p_{T R}$ : probabilidade do evento de cheia; RPunit: risco de prejuízo unitário para o TR considerado; $D_{T R}$ : dano associado à área inundada pelo evento de cheia de tempo de retorno TR; $A i$ : área total inundada para o TR considerado.

A determinação do Risco de Prejuízo $(R P)$ envolve uma análise hidroeconômica. Para a determinação da frequência dos eventos e da área de influência de cada inundação, simulou-se hidraulicamente o comportamento do escoamento das águas no rio Taquari e planície de inundação. Com base nos registros de níveis, ajustou-se a distribuição de probabilidades log-pearson III, possibilitando atribuir para cada mancha de inundação estimada o respectivo tempo de retorno. Os danos foram estimados com base na caracterização socioeconômica da região, dependentes da profundidade de submersão. A figura 1 apresenta como as duas análises se relacionam na estimativa do risco de prejuízo, por meio tanto da curva cota-dano quanto da de probabilidade - dano. $\mathrm{O}$ produto entre $\mathrm{a}$ probabilidade do evento e o dano da respectiva mancha de inundação resulta no risco de prejuízo, e a integral da curva de risco, o prejuízo anual esperado. $\mathrm{O}$ resultado gerado pondera o dano bruto associado a uma dada região com a frequência de ocorrência daquele evento.

\section{Definição do problema e área de estudo}

Bombassaro \& Robaina (2010) identificaram o município de Lajeado (RS) como uma das principais cidades atingidas pelas cheias na bacia Taquari-Antas, tendo como área de contribuição de drenagem cerca de 20 mil km² (Figura 2). 


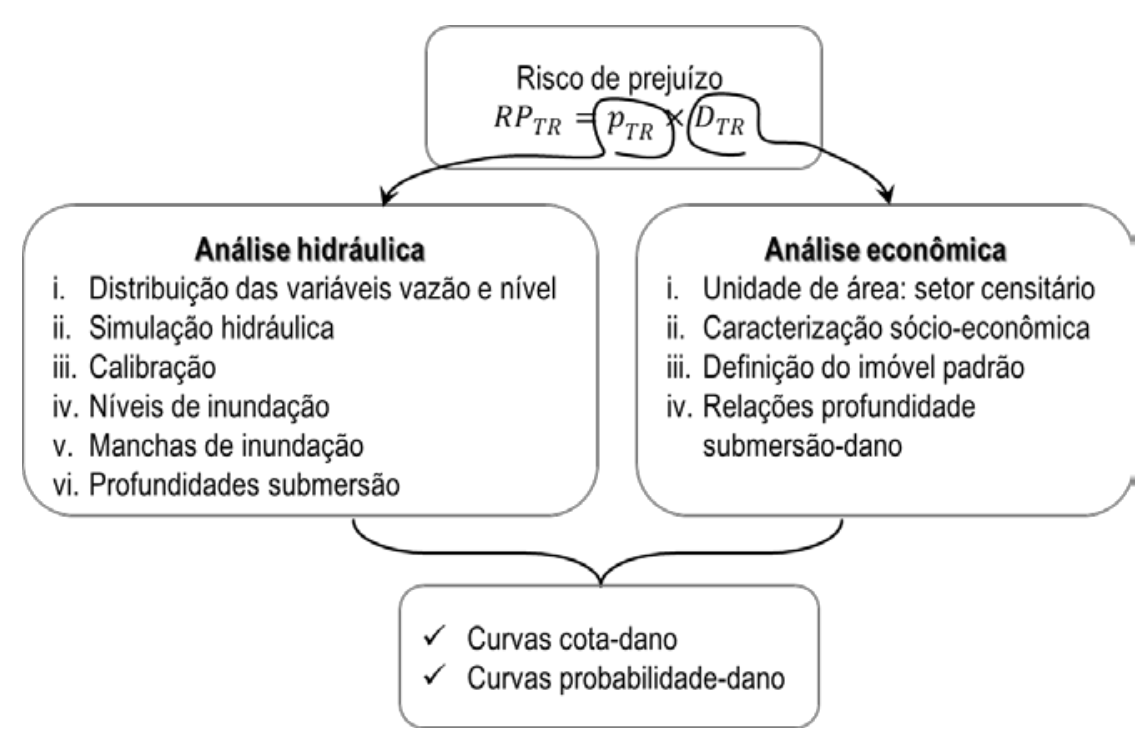

Figura 1 - Relação hidroeconômica da metodologia proposta.

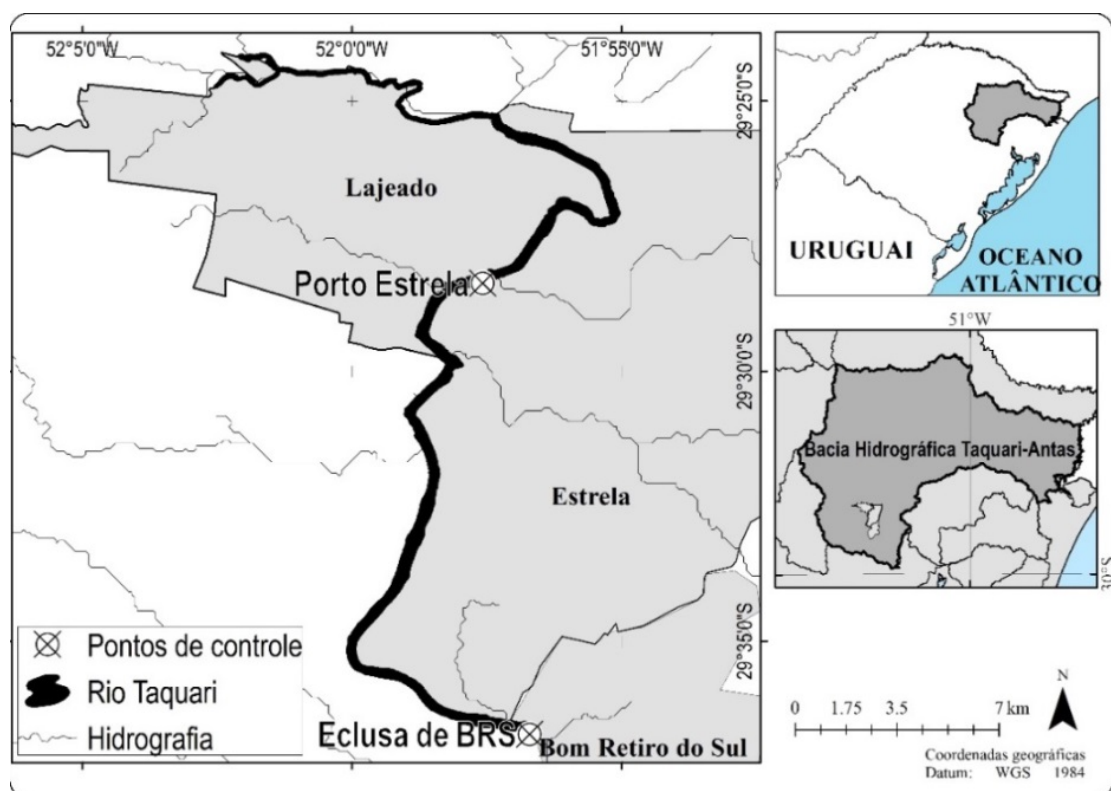

Figura 2 - Localização da área de estudo, com destaque para os municípios de Lageado e Estrela e os pontos de controle para modelagem (Porto de Estrela e Eclusa de Bom Retiro do Sul) e detalhes com a localização da Bacia Hidrográfica Taquari-

Antas no estado do Rio Grande do Sul.

Ao longo de 27 anos (1980 a 2007), foram identificados registros de 24 eventos de inundação, sendo que em metade dos casos foi decretada situação de emergência. Em 2007 foi registrada uma das maiores cheias ocorridas na região, precedida de quatro dias de chuvas e média acumulada na bacia de 246,5 mm, resultando em uma elevação do rio Taquari nas imediações de Lajeado em quase $13 \mathrm{~m}$, atingindo a cota $26 \mathrm{~m}$ na cidade (Eckhardt, 2008). Além das características hidrogeo-morfológicas do Vale do Taquari, um fator relevante para o grande número de registros de inundações é a proximidade da área urbana de Lajeado com o rio Taquari.

O histórico de inundações frequentes acaba contribuindo para a consolidação de uma ampla rede de ações no município, incluindo desde o monitoramento, com diversos projetos de pesquisa por meio do Centro de Informações Hidrológicas (CIH) da Univates, até a prevenção e resposta da Defesa Civil local.

No entanto, pela população ter o conhecimento do padrão dos eventos de inundação e confiar na Defesa Civil, os moradores acabam permanecendo em áreas de risco, muitas vezes incorporando por conta própria medidas adaptativas, como a construção das moradias com primeiro patamar não ocupável (Figura 3), justamente para enfrentar as cheias sem ter que deixar o local. 


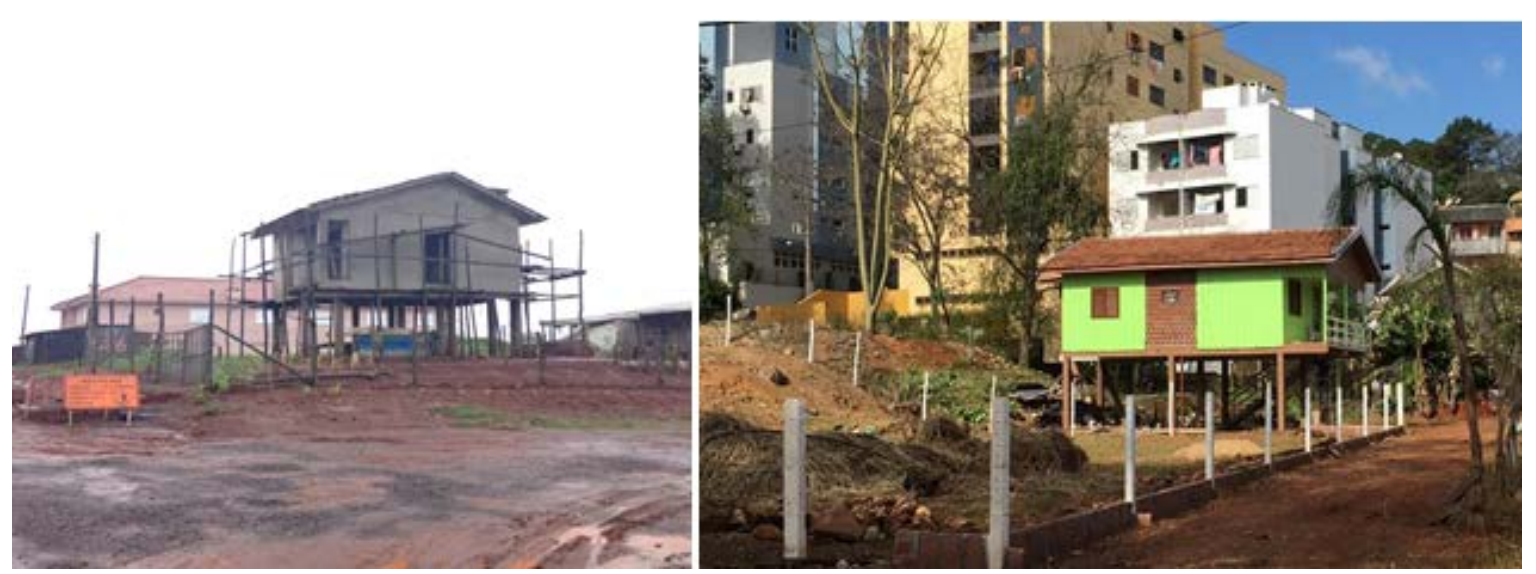

Figura 3 - Adaptação de moradia em áreas com ocorrência de inundação em Lajeado/RS.

A bacia Taquari-Antas apresenta em seu trecho alto hidrografia formada por vales encaixados de alta declividade, o que favorece o escoamento. Em seu trecho médio, o rio apresenta planície com meandros e margens mais largas, além de menores declividades, caracterizando a região do Vale do Taquari, onde está localizado Lajeado. Devido a essas características, é no Vale do Taquari que ocorrem as principais inundações da bacia.

Embora as inundações sejam graduais, pois a planície de inundação é extensa, não apresentando grandes velocidades das águas durante os eventos, a proximidade da ocupação urbana consolidada ao rio Taquari faz com que o município sofra grandes prejuízos inclusive nos eventos de magnitude reduzida.

Os limiares de inundação no município foram identificados em Kurek (2012), classificadas conforme sua magnitude pela tabela 1 .

Tabela 1 - Relação entre cota de inundação e magnitude do evento.

\begin{tabular}{l|l}
\hline Cota (m) & Magnitude \\
\hline 19 a 22 & Reduzida \\
\hline 22 a 25 & Média \\
\hline 25 a 28 & Grande \\
\hline$>28$ & Extrema \\
\hline
\end{tabular}

Fonte: Kurek (2012).

As cotas apresentadas estão relacionadas às medidas na régua do Porto de Estrela, onde o rio Taquari tem seu nível normal na cota $13 \mathrm{~m}$, em função da operação da eclusa de Bom Retiro do Sul (para a navegabilidade desse curso d'água), e cota de extravasamento em 19 m. Segundo Fadel (2015), verifica-se um tempo de recorrência de aproximadamente 2 anos para os eventos de reduzida magnitude ( $22 \mathrm{~m}), 5$ anos para magnitude média (25 m) e 25 anos para grandes magnitudes $(28 \mathrm{~m})$. Tais períodos de recorrência são coerentes com o observado no local. Quase todos os anos pelo menos um nível de alerta pela Defesa Civil é registrado. A inundação ocorrida em outubro de 2015 atingiu quase todos os municípios do Vale do Taquari, interditando diversas áreas de Lajeado. A esse evento se atribuiu um tempo de retorno de quase 4 anos, assim como para os eventos registrados em 2007 e julho de 2011 (Fadel, 2015).

Considerando o histórico de inundações frequentes em Lajeado, ao se propor medidas para sua solução é indispensável considerar as paralisações quase anuais da cidade para enfrentamento das cheias. Isso significa dizer que a variável "frequência" das inundações é tão importante quanto a "magnitude", uma vez que as cheias que atingem até a cota 22 $\mathrm{m}$, mesmo que classificadas com magnitude reduzida, acumulam prejuízos na região por serem muito frequentes.

\section{Discretização da área de estudo}

Conforme Salgado (1995), o tamanho da unidade de análise depende da disponibilidade de dados e do nível de detalhamento desejado. O setor censitário tem sido utilizado por diversos estudos por ser a "menor unidade territorial, formada por área contínua, integralmente contida em área urbana ou rural, com dimensão adequada à operação de pesquisas e cujo conjunto esgota a totalidade do Território Nacional, o que permite assegurar a plena cobertura do País" (IBGE, 2011).

Para a presente pesquisa, foram levantados os setores censitários do município de Lajeado e respectivos dados de população, domicílios, renda, classe social do Censo IBGE 2010, a fim de caracterizar socioeconomicamente as 
diferentes regiões da cidade. Para cada setor, determinou-se a profundidade média e a área inundável.

A população atingida é proporcional à área inundada e os respectivos prejuízos dependentes da profundidade de submersão. Importante ressaltar que mesmo o setor censitário ser a menor unidade territorial oficial, ela nem sempre corresponde à menor escala possível para avaliar a vulnerabilidade.

No caso de Lajeado, foi necessário realizar ainda recortes em setores censitários os quais continham áreas naturalmente não ocupadas (como parques, áreas de preservação, etc.), para corrigir problemas de espacialização da urbanização nestes setores.

\section{Análise hidráulica}

Nessa fase, buscou-se a caracterização da planície de inundação da região, associando probabilidades para diferentes cotas e áreas inundadas.

Como o posto fluviométrico localizado no município de Lajeado encontra-se fora de operação, foram utilizadas as relações geradas no Estudo de Análise Hidrológica das Inundações de Lajeado (Rezende, 1993). Em virtude das inundações frequentes, existe na região uma medição sistemática dos níveis d'água na seção do Porto de Estrela, o que possibilitou validar os ajustes obtidos por Rezende (1993) tanto para a curva-chave das descargas na eclusa de Bom Retiro do Sul (Equação 3), quanto para a relação entre os níveis em Lajeado (régua do Porto) e Bom Retiro do Sul (Equações 4 e 5).

$$
\begin{gathered}
Q=31,834\left(h_{B R S}-0.5\right)^{1,976} \\
h_{L}=7,5524 \times 1,0671^{h_{B R S}}, \quad \text { (3) } \\
\text { para cota d'água em lajeado }\left(\mathrm{h}_{\mathrm{L}}\right) \text { inferior a } 21 \mathrm{~m} \text {, }
\end{gathered}
$$

$$
h_{L}=6,8436 \times 1,0737^{h_{B R S}} \text {, }
$$

para cota d'água em lajeado $\left(\mathrm{h}_{\mathrm{L}}\right)$ superior a $21 \mathrm{~m}$,

Onde:

$Q$ : vazão $\left[\mathrm{m}^{3} / \mathrm{s}\right] ; \mathrm{h}_{\mathrm{BRS}}$ : cota do nível d'água no posto de Bom Retiro do Sul [m].

Com a série de cotas do Porto de Estrela (adjacente a Lajeado), e pelas relações acima descritas, estimaram-se as cotas em Bom Retiro do Sul e posteriormente as respectivas vazões a partir da curva-chave. Uma vez que não existem grandes contribuições de tributários entre o município de Lajeado/Estrela e a eclusa, considerou-se nesse estudo a vazão em Bom Retiro do Sul como igual à de Lajeado. Para essas duas séries (cota e vazão), ajustou-se a distribuição log-pearson III, cujos resultados aparecem na tabela 2.

Tabela 2 - Cotas e vazões máximas para Lajeado.

\begin{tabular}{l|l|l|l|l|l|l|l}
\hline TR (anos) & 2 & 5 & 10 & 25 & 50 & 100 & 200 \\
\hline Cota (m) & 22,75 & 25,15 & 26,58 & 28,28 & 29,17 & 30,62 & 31,74 \\
\hline Vazão (m $\mathbf{3} / \mathbf{s})$ & 7982 & 9369 & 10188 & 11142 & 11604 & 12438 & 13046 \\
\hline
\end{tabular}

Para simular o escoamento das vazões da tabela 2, utilizou-se o programa HEC-RAS (USACE, 2015). O rio Taquari foi dividido em seções e subseções (quando identificada a necessidade de uma maior discretização), e estabelecido como condição de jusante a eclusa de Bom Retiro do Sul (Figura 4). Para a calibração, os coeficientes de rugosidade da calha e margens foram ajustados de forma que o nível d’água na seção de controle do Porto de Estrela estivesse o mais próximo possível, dentro do intervalo de confiança de 95\% da distribuição.

Após a simulação hidráulica, as respectivas áreas de inundação foram delimitadas.

Dependendo da intensidade do evento, o perfil da linha d'água atingiu apenas a calha do rio ou, então, extravasou para a planície de inundação. Com a extensão Geo-Ras foram realizados a interpolação dos perfis de inundação das diferentes seções, a apresentação dos resultados de forma bidimensional e exportação das manchas com os limites da inundação para cada tempo de retorno para SIG.

A profundidade de submersão foi estimada pela diferença da cota da linha d'água com a cota do terreno, para cada unidade de área da mancha. A validação do modelo de simulação foi realizada com a comparação da mancha de inundação simulada para o evento ocorrido em 2008 com marcas históricas registradas em Lajeado (Figura 5) 


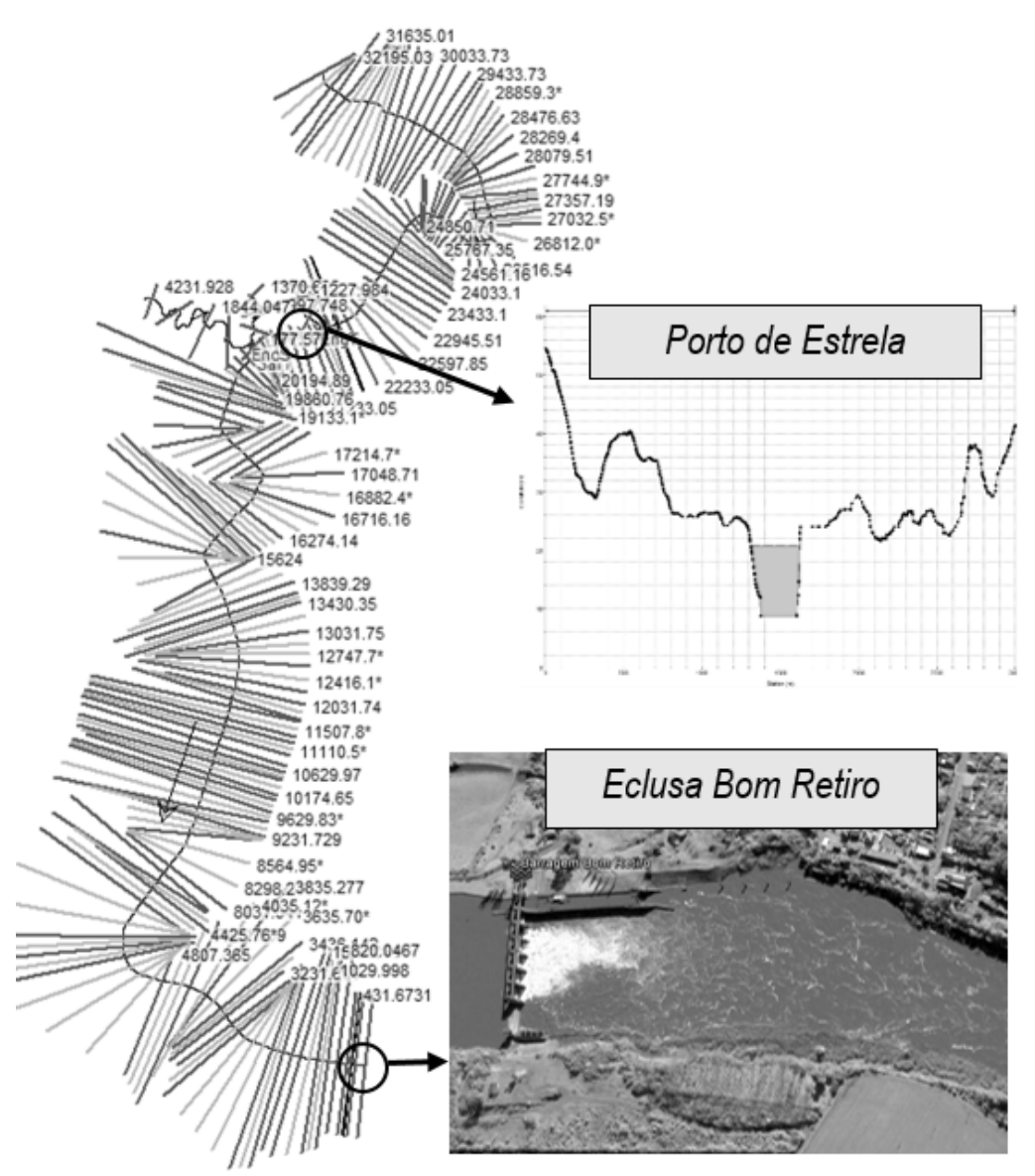

Figura 4 - Esquema da simulação hidráulica.

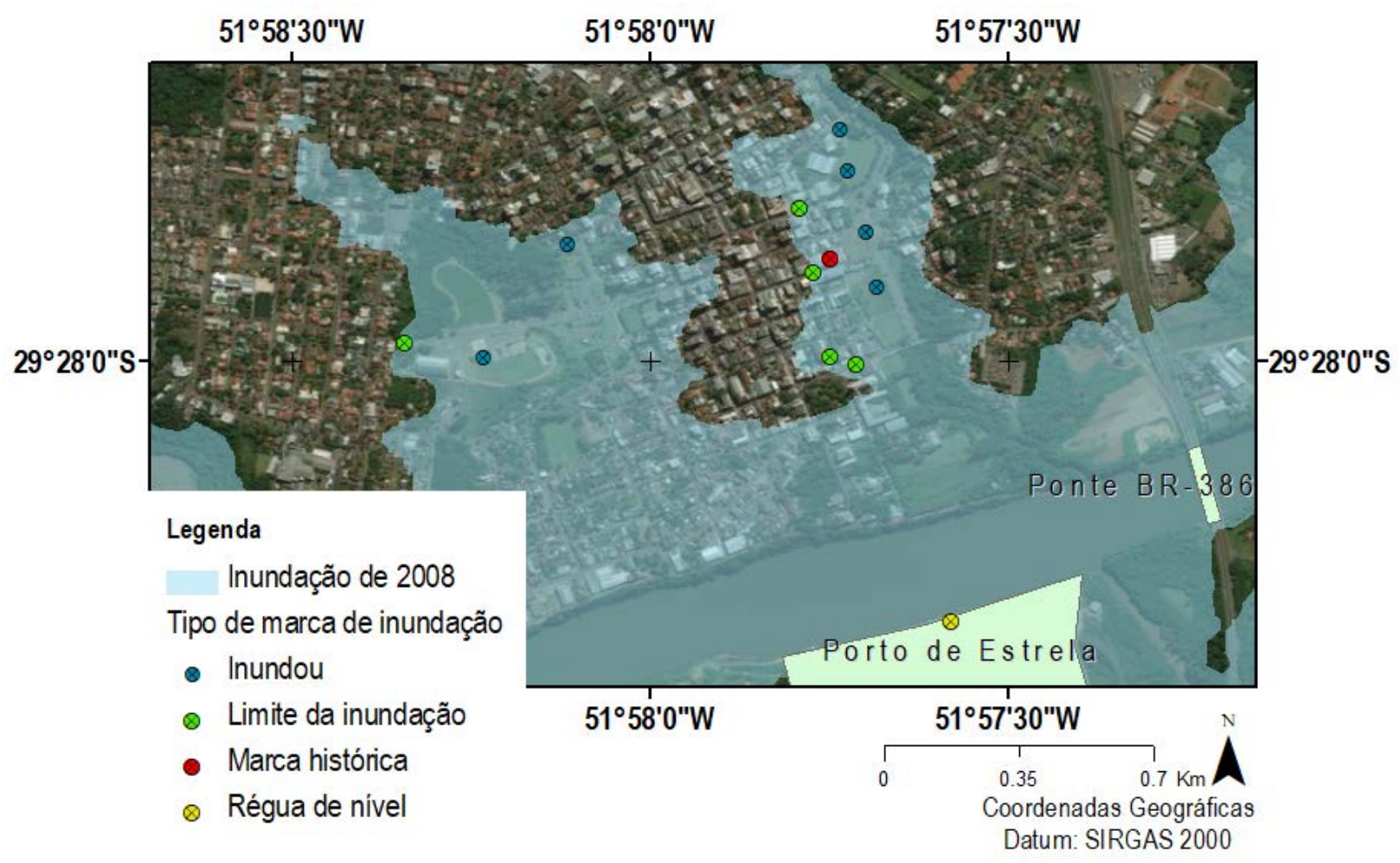

Figura 5 - Localização das marcas de inundação.

\section{Análise Econômica}

Nesta fase, foram associados a cada mancha de inundação os prejuízos potenciais da região. Buscou-se uma metodologia de quantificação dos danos cuja aplicação pudesse ser facilitada com o emprego de dados já disponíveis nos municípios, sem a necessidade de levantamentos de campo nem inventário de danos. Isso 
se deve ao interesse de que se possa replicar, posteriormente, a metodologia para os demais municípios que também sofrem com inundações na região.

As variáveis área do imóvel e Custo Unitário Básico (CUB) foram padronizadas de acordo com a classe socioeconômica de cada setor censitário, sendo utilizados os critérios estabelecidos pela Associação Brasileira de Empresas de Pesquisa (ABEP) (Tabela 3), bem como o critério de Enquadramento das Edificações proposto pela ABNT (Tabela 4), como base.
Tabela 3 - Critério de divisão de classes socioeconômicas de acordo com a renda familiar. Fonte - ABEP (2007).

\begin{tabular}{c|c}
\hline Classe & Renda familiar média (R\$) \\
\hline A1 & 9733,47 \\
\hline A2 & 6563,73 \\
\hline B1 & 3479,36 \\
\hline B2 & 2012,67 \\
\hline C1 & 1194,53 \\
\hline C2 & 726,26 \\
\hline D & 484,97 \\
\hline E & 276,70 \\
\hline
\end{tabular}

Tabela 4 - Características das residências padrão por classe socioeconômica.

\begin{tabular}{|c|c|c|c|c|}
\hline Classe $^{1}$ & Tipo de Residência² & Código $^{2}$ & Área $\left(\mathrm{m}^{2}\right)^{2}$ & CUB $\left(\mathrm{R} \$ / \mathrm{m}^{2}\right)^{3}$ \\
\hline $\mathrm{E}$ & Popular & RP1Q & 39,56 & 1209,77 \\
\hline $\mathrm{D}, \mathrm{C}$ & Padrão Baixo & $\mathrm{R} 1-\mathrm{B}$ & 58,64 & 1188,36 \\
\hline B & Padrão Normal & $\mathrm{R} 1-\mathrm{N}$ & 106,44 & 1474,67 \\
\hline $\mathrm{A}$ & Padrão Alto & $\mathrm{R} 1-\mathrm{A}$ & 224,82 & 1849,38 \\
\hline
\end{tabular}

${ }^{1} \mathrm{ABEP}$ (2007); ${ }^{2} \mathrm{ABNT}$ (2005); ${ }^{3 S I N D U S C O N ~(2015) . ~}$

A metodologia, inicialmente proposta por Tachini (2010), considera o prejuízo por inundações proporcional à profundidade de submersão e às características dos domicílios. O grande facilitador para a aplicação dessa metodologia se dá pela utilização de um imóvel padrão (B2, para Lajeado) para a análise dos danos, o que resulta em dados de prejuízo unitário, sendo este possível de ser extrapolado para quaisquer áreas inundadas, de qualquer padrão construtivo, por meio de um Fator Multiplicador (FM) (Tabela 5).

Tabela 5 - Características das residências padrão por classe socioeconômica

\begin{tabular}{c|c}
\hline Classe & FM (padrão B2) \\
\hline E & 0,25 \\
\hline D & 0,46 \\
\hline C2 & 0,60 \\
\hline C1 & 0,79 \\
\hline B2 & 1,00 \\
\hline B1 & 1,21 \\
\hline A2 & 1,46 \\
\hline A1 & 1,64 \\
\hline
\end{tabular}

Fonte: Tachini (2010).

Esse conceito foi incorporado à metodologia de quantificação de danos do presente estudo, que ponderou o prejuízo para a área inundada de cada setor censitário, para cada mancha de inundação, sendo a soma do estimado para cada setor o resultado para o município de Lajeado como um todo. Para isto, foram analisadas quatro tipologias de danos: os danos às edificações (DE), os danos ao conteúdo dos domicílios (DC), os danos referentes à limpeza (DL) e os danos pelos dias parados (DDP).

As equações e considerações associadas a cada tipologia podem ser consultadas em Fadel (2015). Com os tipos de danos que foram estimados apresentados, o prejuízo total por inundação, para um dado setor censitário i, foi estimado pelas equações 6 e 7 , e o dano unitário, 8.

$D_{\text {total }_{. i}}=D D P_{i}+D E_{i}+D C_{i}+D L_{i}$

$D_{T R}=\sum_{i} D_{\text {total }_{i}}$

$D_{\text {unit }}=\frac{D_{T R}}{A_{i}}$

Sendo $i$ : setor censitário considerado (de 1 ao número de setores atingidos pela inundação); $D_{\text {total }}$ dano total médio de cada setor; $D_{T R}$ : dano total para o TR considerado; $D_{\text {unit }}$ : dano unitário para o TR considerado; Ai: área total inundada para o TR considerado. 


\section{RESULTADOS E COMENTÁRIOS}

\section{Mapeamento das áreas inundáveis}

Tendo como ponto de referência o Porto de Estrela, a tabela 6 apresenta as áreas das manchas de inundação obtidas pela simulação do escoamento das vazões referentes aos tempos de retorno escolhidos.

$\mathrm{Na}$ figura 6 estão os resultados da espacialização das inundações em Lajeado, onde se pode identificar que as cheias impactam o município principalmente junto aos seus três principais arroios (Saraquá, Encantado e Engenho), em decorrência do represamento do escoamento normal das águas pela elevação do nível do rio Taquari.

Tabela 1 - Relação cota-área inundada para cada TR simulado.

\begin{tabular}{c|c|c}
\hline $\begin{array}{l}\text { TR } \\
\text { (anos) }\end{array}$ & $\begin{array}{l}\text { Cota Porto de } \\
\text { Estrela (m) }\end{array}$ & $\begin{array}{l}\text { Área inundação } \\
\left(\mathbf{k m}^{2}\right)\end{array}$ \\
\hline 2 & 22,75 & 4,10 \\
\hline 5 & 25,15 & 5,10 \\
\hline 10 & 26,58 & 6,29 \\
\hline 25 & 28,28 & 6,68 \\
\hline 50 & 29,20 & 7,56 \\
\hline 100 & 30,62 & 7,72 \\
\hline 200 & 31,74 & 7,83 \\
\hline
\end{tabular}

Na figura 7 são apresentadas as estimativas da profundidade de submersão para os TRs 2, 5 e 25 anos.

Embora o modelo tenha sido calibrado com base nas séries medidas de cotas no Porto de Estrela e a verificação, por marcas históricas, acredita-se que manchas estimadas poderiam ser melhor validadas se existissem outros pontos de monitoramento na região, tanto de níveis do rio Taquari quanto de réguas de marcação de inundações no interior do município.

Certamente, de posse de um monitoramento difuso dessas áreas inundáveis, os resultados estimados teriam maior precisão.

\section{Estimativa dos danos}

De posse das áreas inundadas e da profundidade média de submersão para cada setor censitário, chegou-se ao total de dano para cada mancha simulada (Equação 7). Tal dano cresce com o aumento da profundidade, uma vez que indica o prejuízo que poderá ocorrer caso o nível atinja a cota. Da mesma forma, o dano unitário (Equação 8) também é diretamente proporcional à cota de inundação, conforme mostra a curva cota-dano (Figura 8) e a tabela 7.

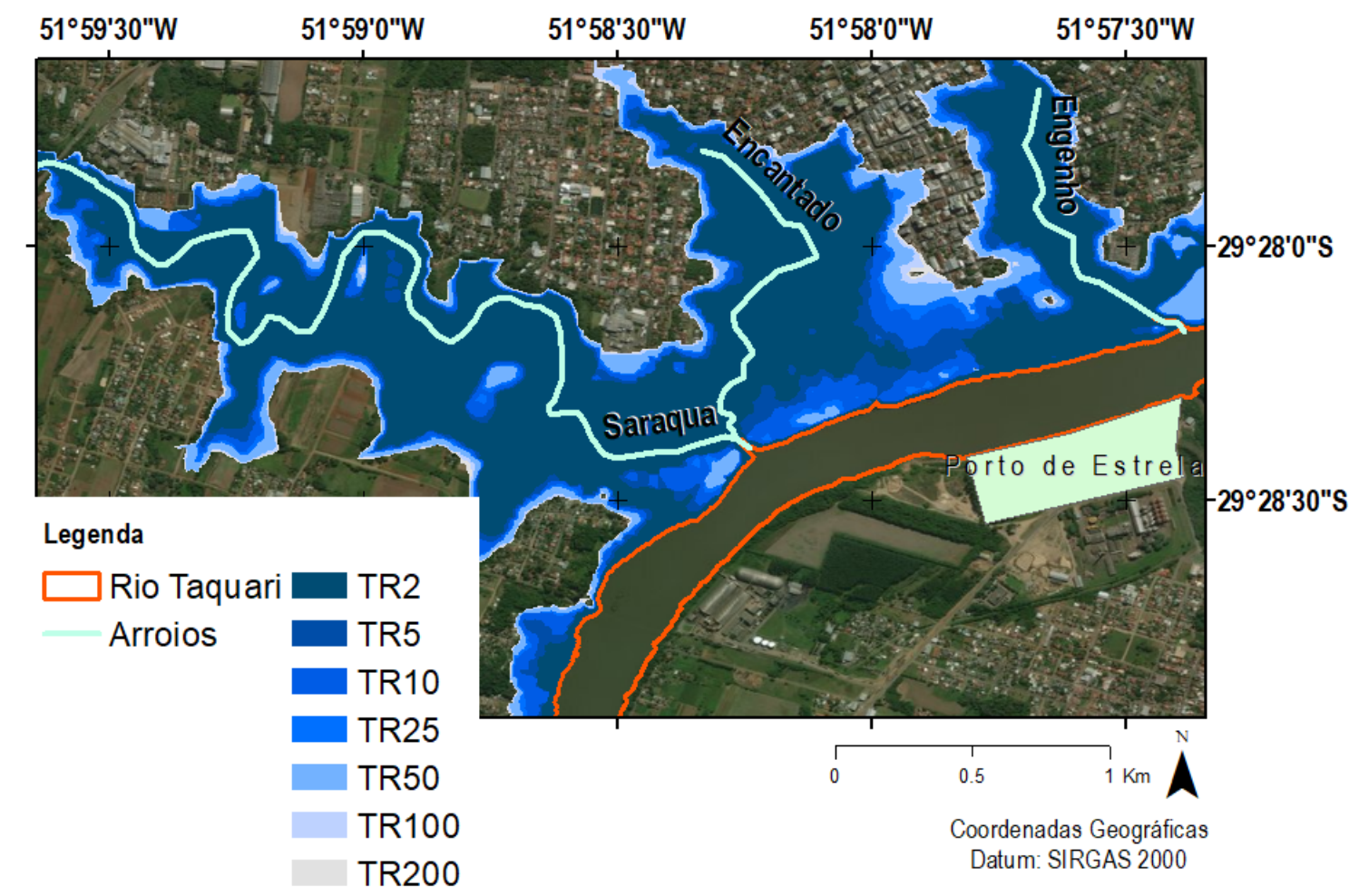

Figura 1 - Mapeamento das inundações conforme Tempo de Retorno (TR) em Lajeado, com a localização dos principais arroios (Saraqua, Encantado e Engenho). 

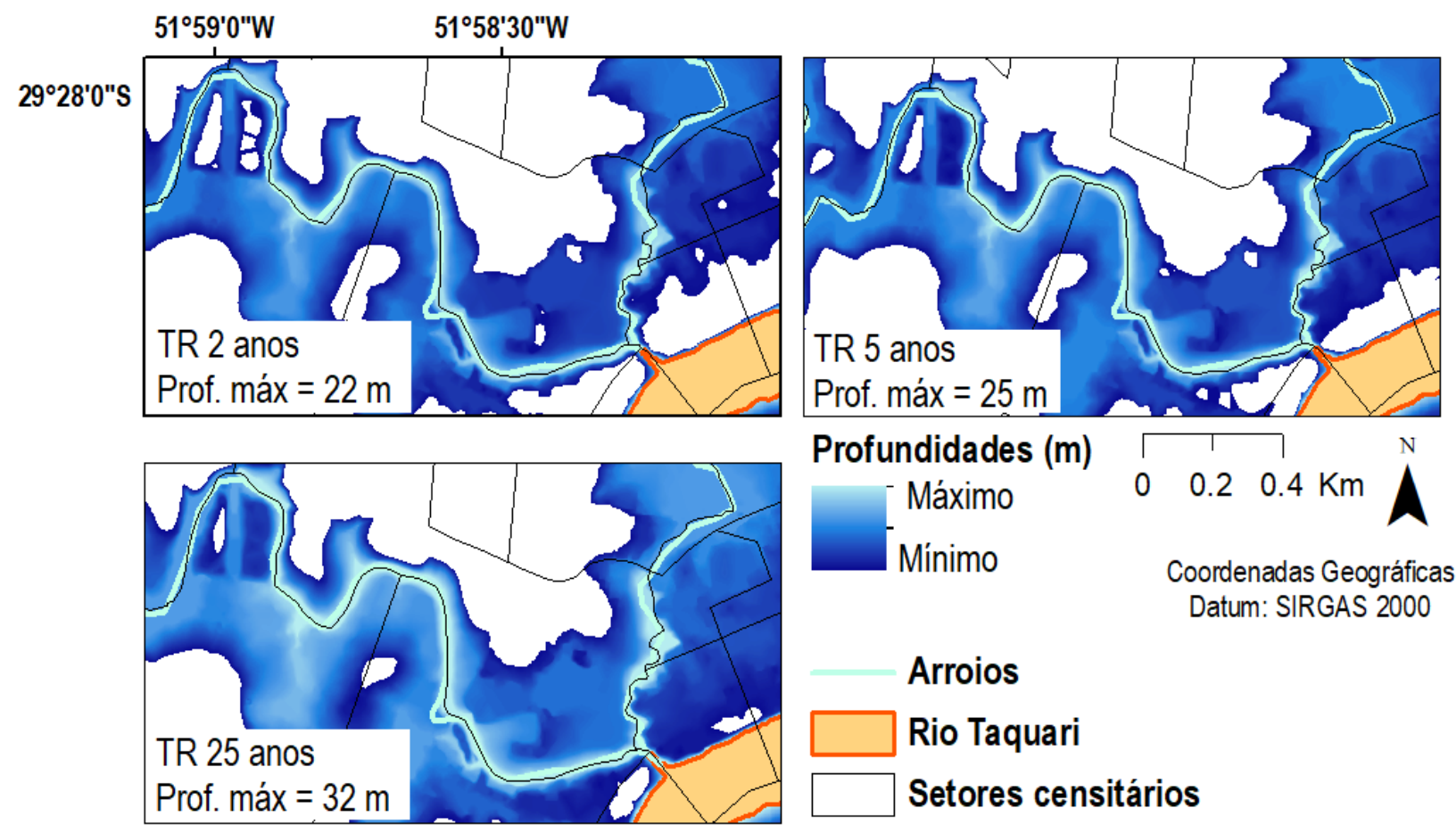

Arroios

Rio Taquari

Setores censitários

Figura 2 - Estimativa das profundidades de inundação para os tempos de retorno 2, 5 e 25 anos.

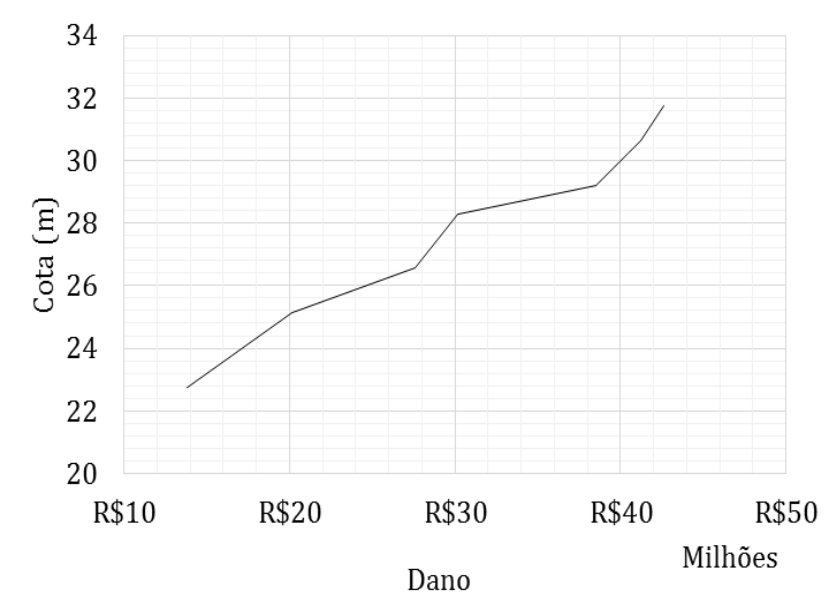

Figura 8 - Curva cota-dano para o município de Lajeado.

Nesta análise, só é considerada a magnitude do evento; ou seja, ao se propor medidas para minimizar os prejuízos decorrentes de uma inundação, pode-se pensar que a melhor alternativa seja optar por uma estrutura capaz de conter a cheia de 200 anos de inundação, pois essa evitaria o maior dano.

Nesta proposta, o benefício pode ser entendido como o "dano evitado", e seria de aproximadamente $\mathrm{R} \$ 5,5$ por metro quadrado protegido (Tabela 7); porém, também se deve atentar para altos investimentos a fim de evitar possíveis prejuízos decorrentes de um evento de baixa probabilidade de ocorrência.
Tabela 7 - Relação cota-dano.

\begin{tabular}{c|l|c}
\hline $\begin{array}{c}\text { Cota no Porto } \\
\mathbf{( m )}\end{array}$ & Dano $\left(\mathbf{1 0}^{\mathbf{6}} \mathbf{R} \mathbf{\$}\right)$ & $\begin{array}{c}\text { Dano unitário } \\
\left(\mathbf{R} \mathbf{\$} / \mathbf{m}^{\mathbf{2}}\right)\end{array}$ \\
\hline 22,75 & 13,82 & 3,37 \\
\hline 25,15 & 20,17 & 3,96 \\
\hline 26,58 & 27,56 & 4,38 \\
\hline 28,28 & 30,15 & 4,51 \\
\hline 29,20 & 38,48 & 5,09 \\
\hline 30,62 & 41,23 & 5,34 \\
\hline 31,74 & 42,58 & 5,44 \\
\hline
\end{tabular}

Embora a análise de medidas para eventos raros seja indispensável, em vista do risco para vidas humanas, a mesma deve ser complementada pela avaliação dos prejuízos acumulados em decorrência de cheias menores, porém frequentes. Estes podem acumular perdas significativas ao longo dos anos, de modo que as medidas para sua mitigação são relevantes ao tornar a área urbana melhor adaptada para convivência com as enchentes.

O risco considera não só a magnitude do evento, mas também sua frequência. $\mathrm{O}$ tempo de retorno atua como um fator peso no montante de prejuízo estimado, resultando em valores explicativos da probabilidade de ocorrência de tal dano. 
No caso de Lajeado, como a faixa de ocupação junto ao rio Taquari é densa e consolidada, sendo constantemente atingida por eventos de inundação (mesmo que de menor magnitude), o fator dano-recorrência é alto. Já para eventos extremos, ainda que o dano seja grande (em função das áreas e profundidades de submersão mais elevadas), a recorrência é pequena, resultando em um risco de prejuízo menor. A tabela 8 apresenta esses resultados, onde o RP e o RP unitário são obtidos com o emprego das equações (1) e (2).

Tabela 8 - Relação risco de prejuízo.

\begin{tabular}{c|c|c}
\hline TR (anos) & $\begin{array}{l}\text { Risco de } \\
\text { prejuízo (R\$) }\end{array}$ & $\begin{array}{l}\text { Risco de prejuízo } \\
\left.\text { unitário } \mathbf{( R \mathbf { S }} \mathbf{m}^{\mathbf{2}}\right)\end{array}$ \\
\hline $\mathbf{2}$ & $6.912 .136,28$ & 4,05 \\
\hline $\mathbf{5}$ & $4.034 .876,52$ & 1,55 \\
\hline $\mathbf{1 0}$ & $2.756 .166,38$ & 0,75 \\
\hline $\mathbf{2 5}$ & $1.206 .025,69$ & 0,30 \\
\hline $\mathbf{5 0}$ & $769.665,18$ & 0,15 \\
\hline $\mathbf{1 0 0}$ & $412.309,08$ & 0,08 \\
\hline $\mathbf{2 0 0}$ & $212.904,29$ & 0,04 \\
\hline
\end{tabular}

A figura 9, apresenta a curva de risco para o município.

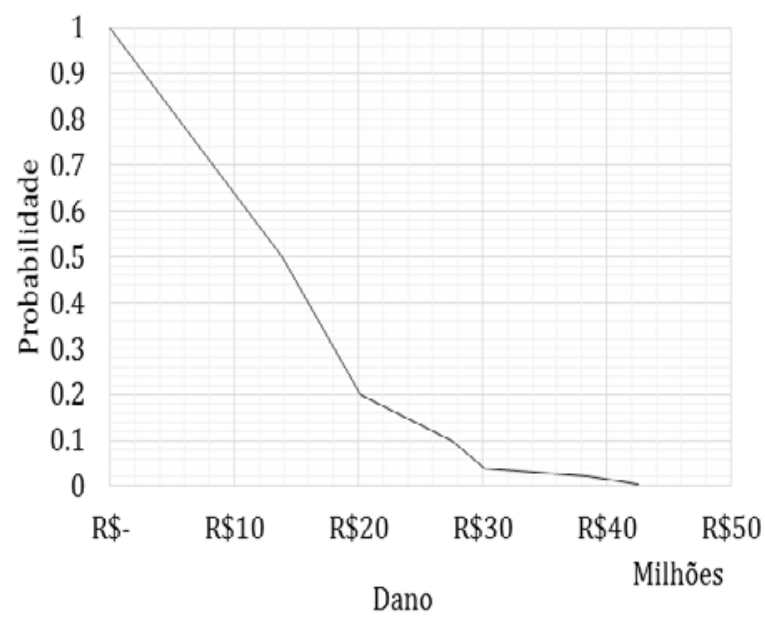

Figura 9 - Curva de risco para o município de Lajeado.

\section{Mapeamento do risco de prejuízo}

A justificativa para se propor medidas de controle com base no risco de prejuízo é que as mesmas possibilitam uma avaliação mais abrangente dos custos dos danos. O resultado é uma distribuição mais eficaz dos investimentos em medidas de mitigação de cheias que sejam efetivas ao longo do espectro de possibilidades, contemplando tanto eventos raros quanto os mais frequentes.

Para o exemplo de aplicação aqui relatado (Lajeado), os maiores riscos estão associados aos eventos mais recorrentes de inundação.

A figuras 10,11, 12 apresentam o mapeamento do risco de prejuízo no município de Lajeado, relacionado aos limiares de Kurek (2012): os eventos de magnitude reduzida são aqueles de até 2 anos de tempo de retorno (Figura 10); os de média magnitude, até 5 anos (Figura 11); os de grande, até 25 anos (Figura 12).

Com a comparação dos três mapeamentos, à medida que são considerados eventos de maior magnitude, o risco de prejuízo diminui de uma forma geral ao longo de todo município. Isso pode ser melhor percebido pela modificação da faixa em que cada setor censitário se enquadra: na simulação do evento de TR 2 anos, há predomínio de riscos de R\$ 300 mil a R\$ 1.000 mil; já para o TR 25 anos, o predomínio é de riscos de até R\$ $100 \mathrm{mil}$.

Tem-se que as inundações extremas, popularmente consideradas geralmente como mais destrutivas, são aquelas com menor risco de prejuízo associado. Já as inundações mais usuais, embora atinjam menores profundidades, apresentam prejuízo associado maior, justamente por serem mais frequentes.

Com esse resultado, já é possível demonstrar que, em um primeiro momento, medidas que preconizem mitigar os efeitos das cheias mais corriqueiras são aquelas que resultam no maior dano evitado. Essas medidas são predominantemente não estruturais, ou seja, que priorizam a adaptação da planície de inundação para o enfrentamento das cheias.

A discretização por setor censitário possibilita identificar quais são os locais mais afetados dentro do município. Uma vez que é uma classificação que considera critérios socioeconômicos, é útil na verificação de quais áreas necessitariam maior atenção da defesa civil, por exemplo, dentro de um mesmo bairro. 


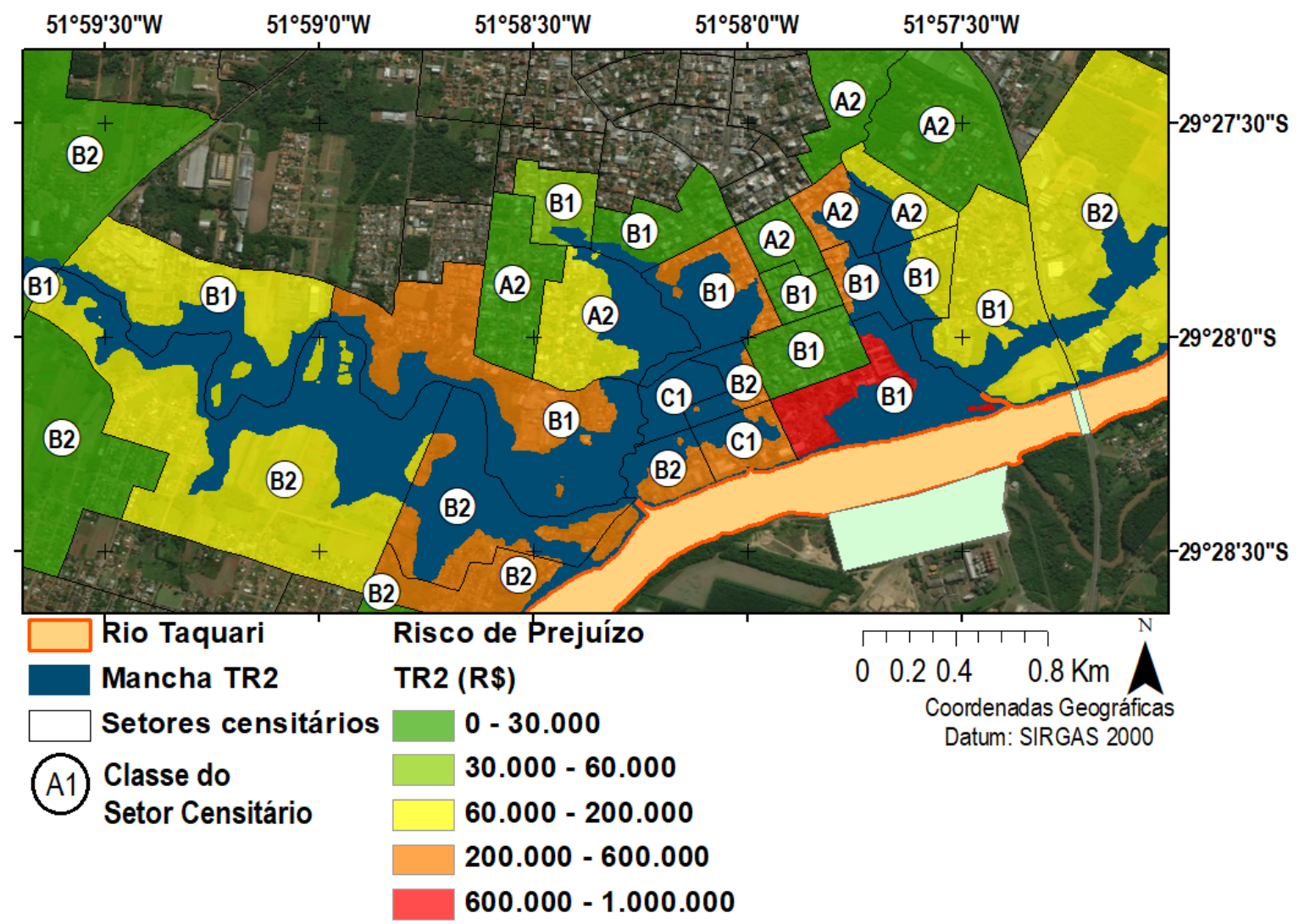

Figura 10 - Mapeamento do risco de prejuízo para eventos de magnitude reduzida (TR de 2 anos), com identificação dos setores censitários e respectivas classes.

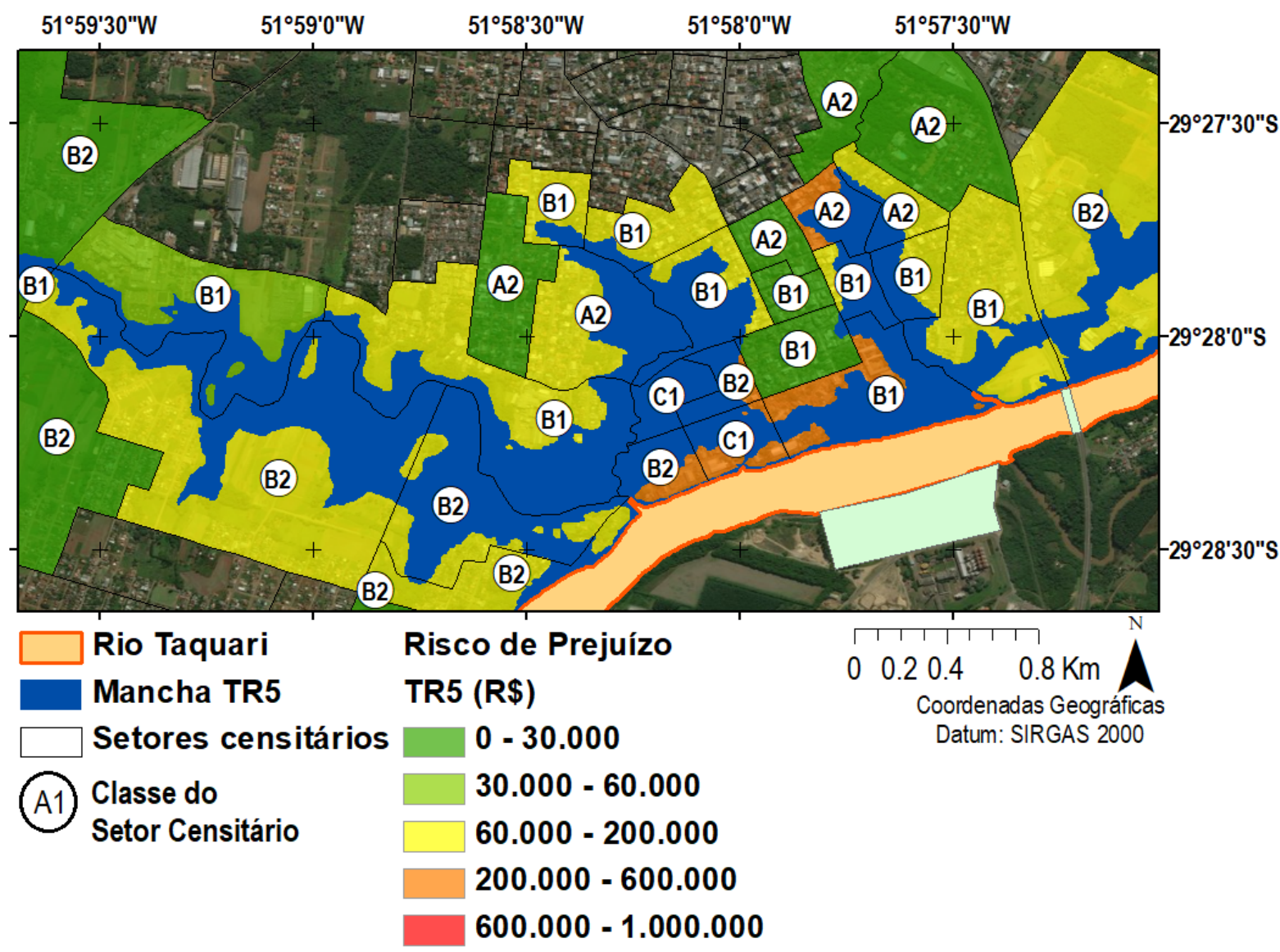

Figura 11 - Mapeamento do Risco de Prejuízo para eventos de magnitude média (TR de 5 anos), com identificação dos setores censitários e respectivas classes. 


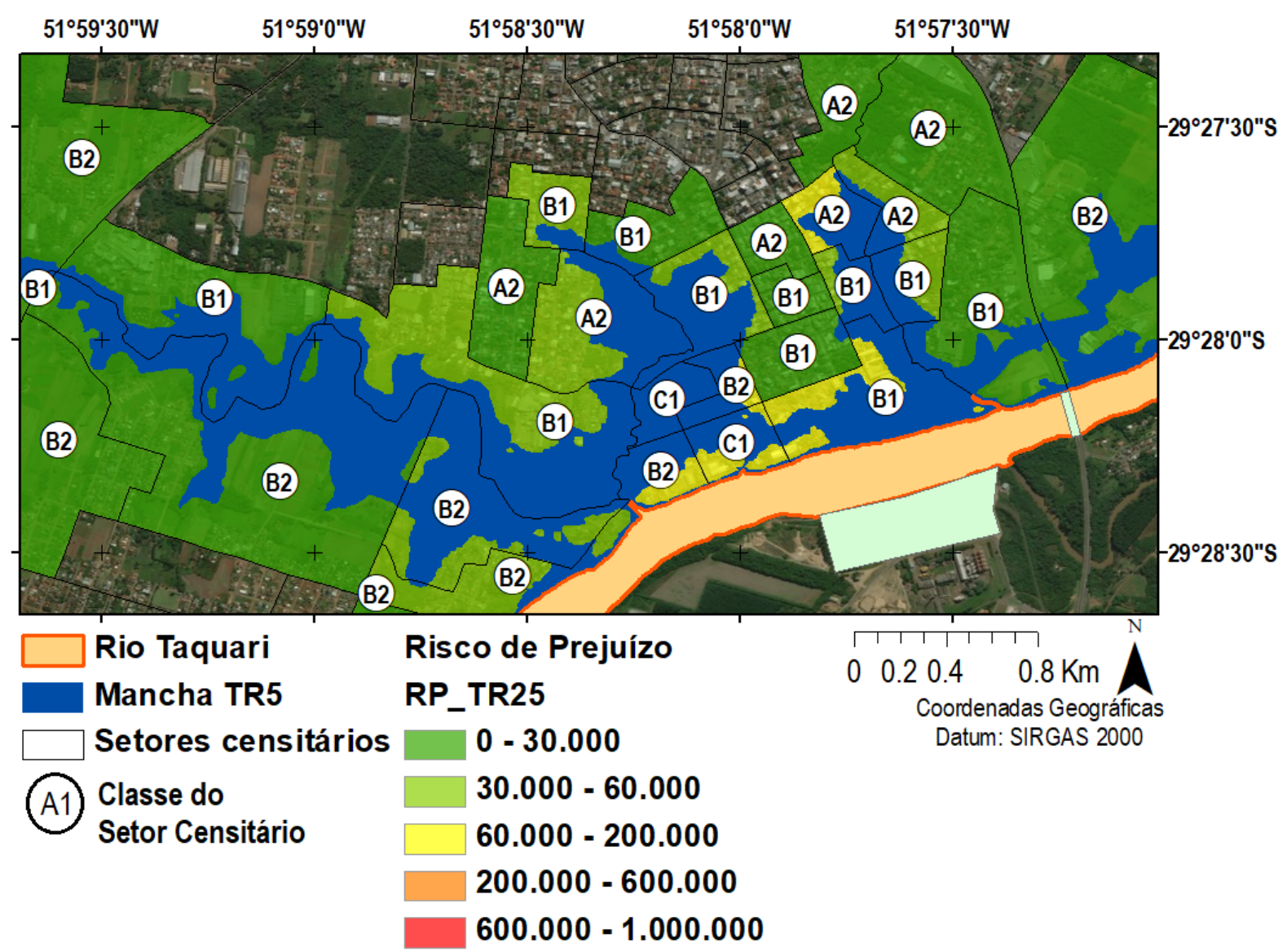

Figura 12 - Mapeamento do Risco de Prejuízo para eventos de magnitude alta (TR de 25 anos), com identificação dos setores censitários e respectivas classes..

Se combinada com sistemas de previsão e alerta, essa ferramenta se mostra eficaz para a identificação prévia de onde a administração pública deverá priorizar os esforços de prevenção, atendimento e reestruturação. Além disso, com tal discretização também é possível que se proponha medidas específicas para cada setor, com base no risco que cada um estaria sujeito.

\section{CONCLUSÕES}

Na gestão de inundação, levar em conta o risco de prejuízo causado por um evento ainda é um conceito relativamente novo, inclusive para países desenvolvidos, como os EUA. Tradicionalmente, as medidas de proteção são baseadas em decisões políticas, que muitas vezes destinam investimentos sem considerar aspectos técnicos que os justifiquem.

Por outro lado, quando da existência de estudos concretos de probabilidade de inundação para definição das áreas suscetíveis, estes dificilmente consideram o risco do prejuízo na escolha de estruturas de proteção. Dessa forma, é comum que a contenção de cheias tenha foco exclusivo em medidas estruturais de grande porte e alto custo para proteção contra eventos raros.

O fator principal para a resolução dessas questões, portanto, está na compreensão da relação entre uso do solo, probabilidade de eventos extremos e danos causados pelas cheias, de modo a permitir o conhecimento do risco de prejuízo. A gestão do risco deverá compreender uma combinação estratégica de medidas estruturais e não estruturais, de forma que se discutam as diversas decisões passíveis de serem tomadas, convergindo para aquela que melhor representa o desejo dos usuários.

Foi efetuado um estudo de mapeamento do risco das inundações na cidade de Lajeado, incorporando o risco de prejuízo - através de um ponderador de frequência de recorrência desse dano - às metodologias já existentes de estimativas do dano por profundidade de submersão. Foram utilizados em conjunto simulação hidráulica e avaliação econômica, de modo a relacionar a frequência de um dado evento às profundidades de submersão ao longo da mancha de inundação e características sócio econômicas de cada unidade de área. 
Os resultados aqui apresentados permitem concluir que, em áreas urbanas com densa ocupação consolidada, nas áreas de maior probabilidade de inundação, o risco pode ser elevado, justificando ações prioritárias para sua mitigação. Já para as localidades mais afastadas do rio, tanto a probabilidade quanto a ocupação diminuem, diminuindo consequentemente o risco.

Esses resultados estão diretamente relacionados com as características de relevo e o padrão de ocupação, que determinam a caracterização dos danos da planície de inundação da região. Para o caso de Lajeado, se não existisse ocupação das áreas de acomodação das cheias de reduzida magnitude, o risco dessas áreas seria menor, indicando outras áreas prioritárias para investimentos em proteção.

A gestão de risco envolve tanto a avaliação da relação probabilidade do evento e prejuízo estimado, quanto a possibilidade da identificação dos locais prioritários de ações e quais medidas seriam mais apropriadas para minimização dos danos. Em Lajeado, o mapeamento dos setores de risco apresentado nas figuras 11, 12 e 13, permite inicialmente confirmar o maior risco de prejuízo para os eventos de cheias mais frequentes, indicando a melhor alternativa para medidas adaptativas, como zoneamento e mudanças no padrão de ocupação.

Além disso, torna-se possível verificar quais setores censitários serão mais afetados pelas cheias, indicando a região central como uma das mais impactadas. Pode-se observar, ainda, que não necessariamente os setores de maior risco correspondem à ocupação de mais baixa renda; portanto, deve-se realizar uma avaliação mais criteriosa, avaliando questões de vulnerabilidade, na tomada de decisão de prioridades de atendimento pela Defesa Civil, por exemplo.

Finalmente, este estudo buscou discorrer acerca de uma complementação às análises de dano que vem sendo comumente realizadas no país. Com a ampliação do monitoramento e consequente melhoramento da representatividade do modelo proposto, esperase que estudos futuros sejam capazes de indicar, para cada setor, qual a melhor alternativa de proteção, com vistas a otimizar os benefícios de ações conjuntas de medidas de gerenciamento das inundações.

\section{AGRADECIMENTOS}

O presente estudo integra do Projeto "Desenvolvimento e apoio à implantação de uma estratégia integrada de prevenção de riscos associados a regimes hidrológicos na Bacia do Taquari-Antas RS”, desenvolvido pelo Centro Universitário de Estudos e Pesquisas sobre Desastres (CEPED/RS) da Universidade Federal do Rio Grande do Sul (UFRGS), com financiamento e apoio da Secretaria Nacional de Defesa Civil (SEDEC) do Ministério da Integração Nacional (MI) e apoio da Coordenadoria Estadual de Defesa Civil do Estado do Rio Grande do Sul (CEDEC/RS). Os autores agradecem à CAPES e CNPq pelas bolsas de Mestrado e de Produtividade em Pesquisa.

\section{REFERÊNCIAS}

ABEP - Associação Brasileira de Empresas e Pesquisa. Critério Brasil. 2005. Disp. em: http://www.abep.org/criterioBrasil.aspx. Acesso em: 9 de fevereiro de 2015.

ABNT - ASSOCIAÇÃO BRASILEIRA DE NORMAS TÉCNICAS. NBR 12721: Critérios para avaliação de custos de construção para incorporação imobiliária e outras disposições para condomínios edilícios - Procedimento. Rio de Janeiro: ABNT, 2005.

BOMBASSARO, M. \& ROBAINA, L.E.S. Contribuição geográfica para o estudo das inundações na bacia hidrográfica do rio Taquari-Antas, RS. Geografias, v. 6, n. 2, p. 69-86, 2010.

BRASIL - Instrução Normativa $\mathrm{n}^{\circ}$ 1, de 24 de agosto de 2012. Estabelece procedimentos e critérios para a decretação de situação de emergência ou estado de calamidade pública pelos Municípios, Estados e pelo Distrito Federal, e para o reconhecimento federal das situações de anormalidade decretadas pelos entes federativos e dá outras providências.
Diário Oficial da União, Poder Executivo, Brasília, DF 30 ago. 2012. n. 169, seção 1, p. 30.

CUNHA, S. \& TAVEIRA-PINTO, F. Aplicação de uma metodologia de análise de risco de inundações à zona ribeirinha do Peso da Régua. In: JORNADA DE HIDRÁULICA, RECURSOS HÍDRICOS E AMBIENTE, 6, 2011, Porto. Anais...Porto: FEUP, 2011. p. 103-112.

DECKERS, P.; KELLENS, W; REYNS, J; VANNEUVILLE, W.; MAEYER, P. A GIS for Flood Risk Management in Flanders. Department of Geography, Faculty of Sciences, Ghent University. Gent, Belgium, 2010.

ECKHARDT, R.R. Geração de modelo cartográfico aplicado ao mapeamento das áreas sujeiras às inundações urbanas na cidade de Lajeado/RS. Porto Alegre, 2008. 116 p. Dissertação (Mestrado em Sensoriamento Remoto) - Centro Estadual de Pesquisa em Sensoriamento Remoto e Meteorologia, Universidade Federal do Rio Grande do Sul.

FADEL, A.W. Incorporação do risco de prejuízo no gerenciamento de medidas de controle de inundação. Porto 
Alegre, 2015. 109p. Dissertação (Mestrado) - Programa de Pós-Graduação em Recursos Hídricos e Saneamento Ambiental, Universidade Federal do Rio Grande do Sul, Instituto de Pesquisas Hidráulicas.

FOUDI, S.; OSÉS-ERASO, N.; TAMAYO, I. Integrated spatial flood risk assessment: The case of Zaragoza. Land Use Policy, n. 42, p. 278-292, 2014.

IBGE - Instituto Brasileiro de Geografia e Estatística. Base de informações do Censo Demográfico 2010: Resultados do Universo por setor censitário. Rio de Janeiro: Centro de Documentação e Disseminação de Informações. 2011.

KUREK, R.K.M. Avaliação do tempo de retorno dos níveis das inundações no Vale do Taquari, RS. Lajeado, 2014. 85 p. Trabalho de Conclusão de Curso (Curso de Engenharia Ambiental) - Centro Universitário UNIVATES.

MACHADO, M.L.; NASCIMENTO, N.; BAPTISTA, M.; GONÇALVEZ, M.; SILVA, A.; LIMA, J.C.; DIAS, R.; SILVA, A.; MACHADO, E.; FERNANDES, W. Curvas de danos de inundação versus profundidade de submersão: desenvolvimento de metodologia. Revista de gestão de água da América Latina (REGA), Porto Alegre, v. 2, n. 1, p. 3552, jan./jun. 2005.

NAGEM, F.R.M. Avaliação econômica dos prejuízos causados pelas cheias urbanas. Rio de Janeiro, 2008. 114p. Dissertação (Mestrado em ciências em engenharia civil), Universidade Federal do Rio de Janeiro.

PENNING-ROWSELL, E.C. \& CHATTERTON, J.B. The benefits of flood alleviation: A manual of assessment techniques. England: Saxon House, 297 p., 1977.

REZENDE, B.S. Análise hidrológica sobre as ocorrências de inundações na área urbana da Cidade de Lajeado. Lajeado. 1993.
SALGADO, J.C.M. Avaliação econômica de projetos de drenagem e de controle de inundações em bacias urbanas. Rio de Janeiro, 1995, 113p. Dissertação (Mestrado em ciências em engenharia civil), Universidade Federal do Rio de Janeiro.

SINDUSCON - Custo Unitário Básico do RS. Disponível em: http://www.sinduscon-rs.com.br/produtos-e-

servicos/pesquisas-e-indices/cub-rs/. Acesso em: 22 de julho de 2015

TACHINI, M. Avaliação de danos associados às inundações no município de Blumenau. Florianópolis, 2010. 167p. Tese (Doutorado), Universidade Federal de Santa Catarina.

TUCCI, C.E.M. Hidrologia: Ciência e Aplicação. Porto Alegre: Editora UFRGS, 2009. 943 p.

USACE. U.S. Army Corps of Engineers Hydrologic Engineering Center. Computer software for hydrologic engineering and planning analysis procedures. Disp. em: http://www.hec.usace.army.mil/software/. Acesso em: 3 de dezembro de 2015

VAZ, V.B. Avaliação do custo do risco de inundações urbanas: estudo de caso dos danos de inundação em Porto Alegre - RS. Porto Alegre 2015. 148 p. Dissertação (Mestrado), Universidade Federal do Rio Grande do Sul.

GOERL, R.F. \& KOBIYAMA, M. Redução dos desastres naturais: desafio dos geógrafos. Ambiência - Revista do Setor de Ciências Agrárias e Ambientais. Guarapuava (PR), v.9 n.1 p. 145 - 172, Jan./Abr. 2013. ISSN 1808 0251.

Submetido em 20 de setembro de 2016 Aceito em 23 de março de 2017 